\title{
EVALUATION OF STRESSES AND RETENTION IN TWO DIFFERENT TYPES OF BAR ATTACHMENT USED IN IMPLANT RETAINED MAXILLARY OBTURATOR
}

\author{
Amr Mohamed Ismail Badr* and Ahmed Gamal Ahmed Hassan*
}

\begin{abstract}
Purpose: The aim of this study was to compare the stresses and retention force of two different attachment systems in implant retained maxillary obturator.

Material \& Methods: an acrylic model was constructed to simulate edentulous case with maxillary defect and three implants were inserted in the pre-maxillary region. The obturator was constructed with the first design bar with equator attachment (BEA) and screwed to the implants. The retention was measured at the base line and after 90,270,540,810,1080,1620,2160 cycles of insertion and removal respectively. Then the second design bar and clip attachment was constructed, screwed and retention testing procedures repeated as that for the first design. Universal testing machine was used for measuring the retentive forces of each retainer type. The vertical static load of 60 and $90 \mathrm{~N}$ was applied (loading machine) at three loading points on the obturator prosthesis for the two bar designs. The readings were tabulated and statistically analyzed.
\end{abstract}

Results: Two-factor ANOVA followed by pair-wise Newman-Keuls post-hoc tests were performed to detect significance between variables (Attachment type and aging). Bar and clip design recorded slightly lesser retention force than that of BEA at base line and at all cycles of insertion and removal but with no significant difference between the two designs. But regarding the effect of aging within each group; there was a significant difference at different cycles of insertion and removal. But regarding the stress analysis Bar and clip recorded to some extent less microstrain values than BEA in most of surfaces at different points of loading.

Conclusion: The retention force of Bar and clip was slightly lesser than BEA at any given cycle of insertion and removal. Reduction of mean retentive force continues to occur over time within each group. Bar and clip recorded less micro-strain values than BEA at most of the surfaces specially when applying the load on the posterior intact side.

\footnotetext{
* Lecturer of Prosthodontic Department, Minia University
} 


\section{INTRODUCTION}

Acquired maxillofacial defects are those that are created by other than congenital/developmental influences. These are more often related to surgical intervention for the elimination of disease or trauma resulting in significant alteration of the normal anatomic features of the oral and facial structures. The defect may be in the form of a small opening resulting in communication between the oral cavity and the maxillary sinus, or may include portion of the hard and soft palate, alveolar ridge and the floor of the nasal cavity. ${ }^{(1,2)}$

Maxillofacial prosthesis plays a key role in the overall rehabilitation of patients with these defects. The prosthesis constructed to repair the defect is termed a maxillary obturator. Obturator is considered a better choice for the patients of large maxillary defects in comparison to surgical rehabilitation. ${ }^{(3)}$

The goals of prosthetic rehabilitation for total and partial maxillectomy include restoring the missing structures and acts as a barrier preventing communication among the various cavities. ${ }^{(4)}$

Construction of a maxillary obturator for any surgical defect requires optimum retention, support and stability but these functions difficult to be obtained using conventional simple obturator particularly in edentulous patients. ${ }^{(5,6)}$

Placements of osseointegrated implants have a dramatic effect on the function of the prosthesis for the edentulous hemi-maxillectomy patients. Implants provide retention, enhance support, and improve stability of the obturator prosthesis. ${ }^{(7)}$

It is preferred to unite the implants with a rigid bar, with retentive elements attached to it. The retentive elements should be designed to direct occlusal forces along the long axis of the implant fixtures. Most damaging forces on implants can result from occlusal loading. ${ }^{(8)}$

Bar attachment provides a direct mechanical attachment between the removable prosthesis and the supporting fixtures, so fixtures can be connected for mutual support. It acts as a splint between abutments and can also provide either rotational movement between the bar and the overlying sleeve (bar joint) or rigid fixation (bar unit). ${ }^{(9)}$

The bar provide implant splinting and prosthesis support while retention is obtained from two or more stud attachments placed on top of the bar, at its distal end, on the labial or lingual aspect or at a combination of these locations. The location of the stud attachment depends mainly on the available inter-arch distance and the implant tilt. ${ }^{(10)}$

The introduction of osseointegrated dental implants has greatly enhanced the prosthetic prognosis for edentulous patients especially those with maxillary defects since they can be used as anchorage to provide support, stability and retention. ${ }^{(11)}$

The aim of this study was to compare the stresses and retention force of two different attachment systems in implant retained maxillary obturator.

\section{MATERIAL AND METHODS}

A model was constructed in acrylic resin (luction199.dentspy1york division. DENTSPLY international inc. york p.a 1740.5) to simulate completely edentulous case with maxillary defect (class I Armany).

All undercuts were eliminated .Three screw indirect implants (Spectra system,implant direct 1lc,27030 malibu hills road ,calabasashills CA913101,US) (13mm length $\& 3.75 \mathrm{~mm}$ diameter) were inserted in the pre-maxillary region of the intact side perpendicular to the residual ridge area.

A mix of chemically-activated acrylic resin (Acrostone,WHW,England) was introduced to the drilled implant sites and the implants were tightened. A single cast metal chrome cobalt framework (Wironium Beggo Bremer bremer GoldschlÖgerei whilhelm, bremen, Germany) was fabricated to reinforce the experimental obturator. 


\section{Bar and Equator (BEA) construction}

Three plastic copings (Spectra system, implant direct llc, 27030 malibu hills road, calabasashills CA913101, US) were fastened to the implants using the tightening screws. A bar was waxed- up to connect the copings. Two equator (Rhein 83 srlviaE.Zago8_40128 BOLOGNA) attachments $(2,1 \mathrm{~mm}$ height and 4,4mm width) were placed between plastic copings using dental surveyor.

\section{Bar and clip construction}

The same procedure as previous instead of the equator attachments, two plastic burn-out bars (Steg-Clip-System, Oraltronics, Dental Implant Technology GmbH, Bremen, Germany) were used connecting the three plastic copings.

The two waxed- up designs were cast in cobaltchromium alloy, finished and polished. (Fig 1a, 1d)

\section{Construction of the metal framework}

The model was duplicated into an investment material to obtain a refractory cast. The obturator framework was waxed- up and a wax ring of $4 \mathrm{~mm}$ diameter was fixed on the center of the arch for future retention measuring. The waxed-up framework was completely invested, cast, finished and polished.

\section{Construction of the obturator}

The model was duplicated to produce processing stone model. Wax was added to the defect side, fitting surface of the metal framework and over its borders. The waxed framework was flasked, wax was eliminated, and the flask was opened, packed by heat- activated acrylic resin, processed then finished and polished.

Series of holes $(2 \mathrm{~mm})$ depth were created in the residual ridge, palate and defect side of the model
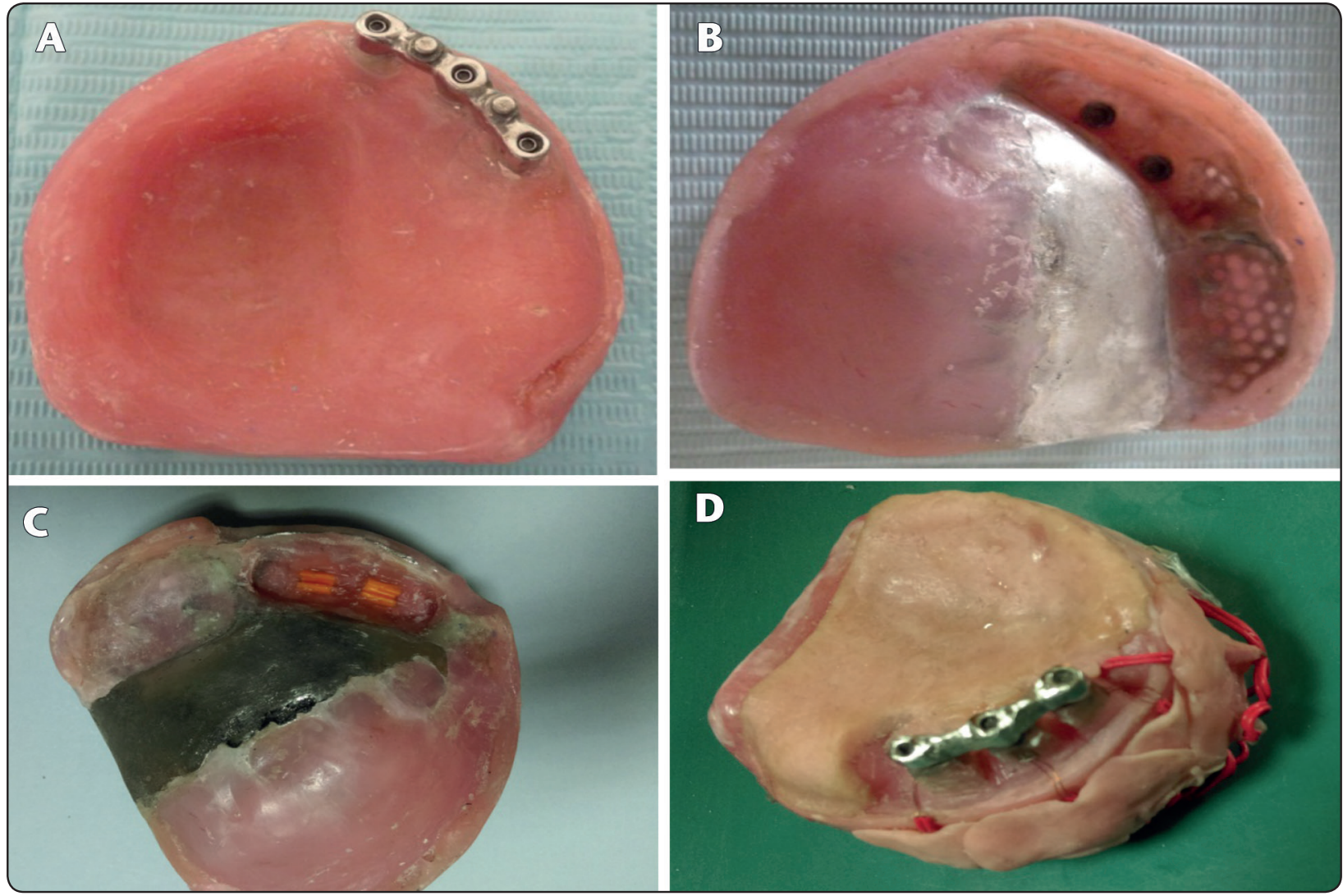

Fig. (1) a) Cast BEA., (b) Denture fitting surface having two metal housings (c) Denture fitting surface having two clips., (d) Cast Bar and Clip 
using round bur (number 5). Cylindrical stone was used to remove the acrylic resin between the holes. This modification of the cast created a mould cavity which was packed with self-cured silicon soft liner.

\section{Picking- up procedure}

Nylon caps and metal housings were seated in place over the Equator patrix. The obturator was seated properly. Chemically- activated acrylic resin at dough stage was applied to the fitting surface of the obturator. The obturator was seated over the model to pick -up the two Equator metal housings. Pressure was applied until complete curing of the acrylic resin. After complete setting of acrylic resin the obturator was removed, checked and finished. (Fig 1b, 1c)

\section{Retention test application}

Universal testing machine (Fig 2a) was used for measuring the retentive forces of each retainer type. The machine consists of vertical arm with metal cylinder that was hooked to the metal ring of the obturator. Tensile forces were applied to the metal ring of the obturator during the retention test. Gradual tensile load was recorded, and maximum retentive force was measured.

Based on the assumption that a patient removes the prosthesis three times daily. Retention was evaluated at baseline (T0), after 90 cycle(T1),
270 cycles(T2), 540 cycles(T3), 810 cycles(T4), 1080 cycles(T5), 1620 cycles (T6) and 2160 cycles (T7).

After making the retention test of the bar with equators, The new bar was tightened to the implant, the two metal housings and nylon caps were removed from the fitting surface of the obturator and replaced by two clips. Then the same procedures were made as previously for measuring the mean retentive forces at the same cycles as that for BEA.

\section{Stresses evaluation around the three implants}

Model preparation for strain gauge installation:

The acrylic around each implant was prepared into a box shaped area using fissure bur. $1 \mathrm{~mm}$ thickness of acrylic resin all around each implant was left .The surfaces were prepared flat and parallel to the long axis of the implants in all direction.

The prepared sites were smoothened using 400 grit silicon carbide paper and a fine sand paper to develop a surface texture suitable for strain gauge bonding.

The strain gauges (Kyowa strain gauge, KFG3-120-c1-1111M2R, Japan) used in this study had a gauge length $1 \mathrm{~mm}$. Resistance was $120,4 \mathrm{ohm}$ and gauge factor was $2.09 \%$.Four sites were selected for installation of strain gauges to monitor the effect of the vertical load applied on both bar designs.

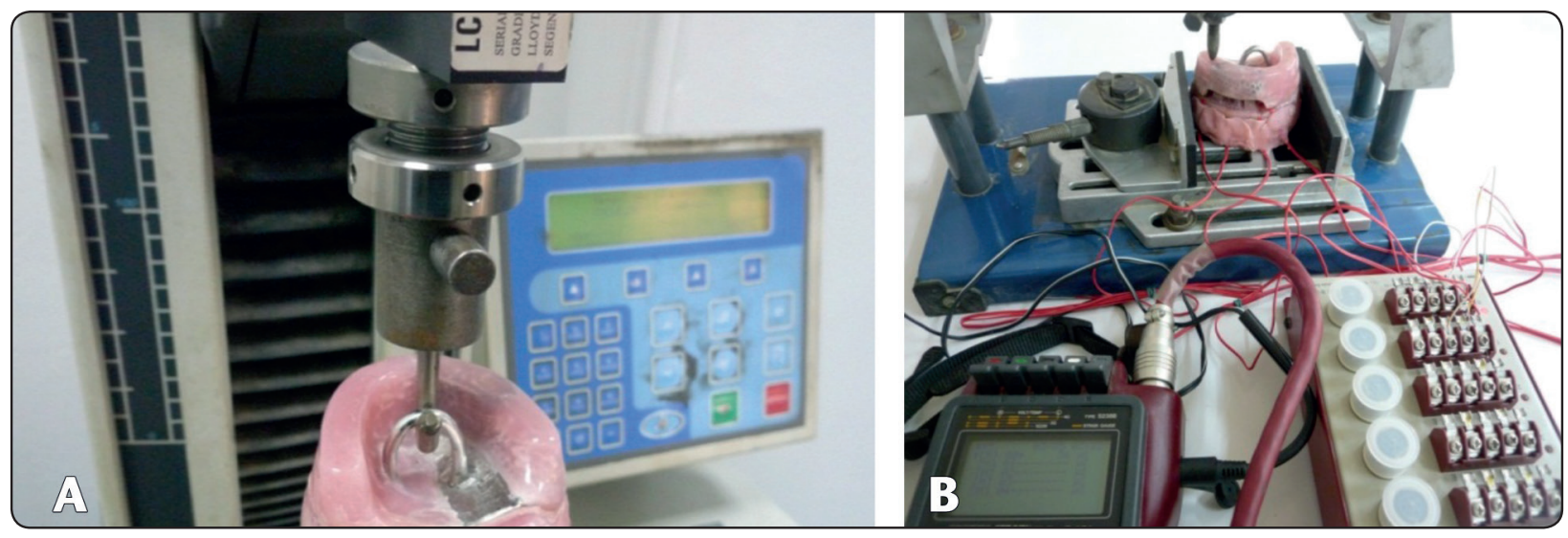

Fig. (2) a) Lloyd universal testing machine. b) Loading device during load application 


\section{The selected sites were:}

- Mesial surface of the mesial implant.

- Buccal and palatal surfaces of the middle implant.

- Distal surface of the distal implant.

\section{Installation of strain gauges:}

The gauges were bonded to their respective sites on the model using a cyanoacrylate based adhesive (CC-33 strain gauge cement, Kyowa electronic instruments co., Japan).

Light pressure was applied against the bonded gauges for 5minutes using large ball burnisher.

The strain gauges were left for 24 hours to ensure complete curing of the adhesive.

The lead wires of the gauges were secured permanently in place using acrylic resin to prevent any possible movement or accidental disconnection of the wires. The wires were labeled for indicating the areas to be measured.

\section{Micro-strain recording}

The vertical static load of 60 and $90 \mathrm{~N}$ was applied at the previously determined loading points on the obturator prosthesis for the two bar designs by the loading device.(Fig 2b)

The experiment started with no load, where the Wheatstone bridge for each of the four strain gauges was null and checked for calibration.

The specific load was then applied at the desired loading points each point at a time. The load was applied by turning the handle on to the desired number of cycles.

Once the load was completely applied, the readings were recorded in microstrain units from the multi-channel strain indicator. The experiment was repeated four times for each point of application and load magnitude. Enough time was allowed between each reading to allow the strain gauges to be zero balanced before making the next reading.

\section{Statistical analysis}

Data analysis was performed in several steps. Initially, descriptive statistics for each group results. Two-factor ANOVA followed by pair-wise Newman-Keuls post-hoc tests were performed to detect significance between variables (Attachment and aging). Student t-test was performed to detect significance between main groups at different aging cycle. Statistical analysis was performed using Aasistat 7.6 statistics software for Windows (Campina Grande, Paraiba state, Brazil). P values $\leq 0.05$ are considered to be statistically significant in all tests.

\section{RESULTS}

\section{I) Effect of Attachment type and Mechanical aging}

Two-factor ANOVA followed by pair-wise Newman-Keuls post-hoc tests were performed to detect significance between variables (Attachment and aging).

Descriptive statistics of the retention force results measured in Newton for implant retained obturator as function of attachment and mechanical aging were presented for both groups in table (1),(2).

The mean retentive force of Bar and Equator attachments decreased by time from $14.42 \pm 0.62$ at base line to $4.82 \pm 1.15$ after 2160 cycle of insertion and removal. (Table 1).

The mean retentive force of Bar and Clip attachments decreased by time from $12.35 \pm 1.05$ at base line to $4.38 \pm 0.35$ after 2160 cycle of insertion and removal. (Table 2).

So there was a significant difference between most of the cycles from the base line till the end of cycles (2160) for each group separately.

Student t-test was performed to detect significance between main groups at different aging cycle. From the data obtained and comparison between both groups regarding the mean retentive force, there was no significant difference between both group throughout the different cycles of insertion and removal. (Table 3) (Fig 3) 
TABLE (1) The mean retentive force of Bar with Equator attachments at different cycles

\begin{tabular}{|c|c|c|c|c|c|}
\hline & \multicolumn{5}{|c|}{ BEA implant- retained obturator } \\
\cline { 2 - 5 } & Mean & \pm SD & Difference & Rank & Statistics (p value) \\
\hline Baseline & 14.42 & \pm 0.62 & -- & A & A \\
\hline 90 cycle & 13.75 & \pm 0.77 & 0.67 & B \\
\hline 270 cycle & 9.14 & \pm 0.28 & 4.61 & B \\
\hline 540 cycle & 8.84 & \pm 0.75 & 0.30 & C \\
\hline 810 cycle & 7.52 & \pm 0.41 & 1.32 & C \\
\hline 1080 cycle & 6.86 & \pm 0.50 & 0.66 & D \\
\hline 1620 cycle & 5.81 & \pm 2.03 & 1.05 & $\mathrm{D}$ & \\
\hline 2160 cycle & 4.82 & \pm 1.15 & 0.99 & & \\
\hline
\end{tabular}

Different letters indicating statistical significance

ns; non-significant

*; significant

TABLE (2) The mean retentive force of Bar and Clip attachment at different cycles

\begin{tabular}{|c|c|c|c|c|c|}
\hline & \multicolumn{5}{|c|}{ BAR AND CLIP implant- retained obturator } \\
\hline & Mean & $\pm \mathrm{SD}$ & Difference & Rank & Statistics ( $\mathrm{p}$ value) \\
\hline Baseline & 12.35 & \pm 1.05 & --- & A & \multirow{8}{*}{$<0.001 *$} \\
\hline 90 cycle & 11.28 & \pm 0.88 & 1.07 & $\mathrm{~B}$ & \\
\hline 270 cycle & 7.77 & \pm 0.63 & 3.51 & $\mathrm{C}$ & \\
\hline 540 cycle & 7.46 & \pm 0.43 & 0.31 & $\mathrm{C}$ & \\
\hline 810 cycle & 6.46 & \pm 0.52 & 1.00 & $\mathrm{D}$ & \\
\hline 1080 cycle & 6.36 & \pm 0.23 & 0.10 & $\mathrm{D}$ & \\
\hline 1620 cycle & 4.41 & \pm 0.71 & 1.95 & $\mathrm{E}$ & \\
\hline 2160 cycle & 4.38 & \pm 0.35 & 0.03 & $\mathrm{E}$ & \\
\hline
\end{tabular}

Different letters indicating statistical significance ns; non-significant $\quad$ *; significant

TABLE (3) Comparison of retention force results (Mean \pm SD) for both groups as function of attachment and mechanical aging

\begin{tabular}{|c|c|c|c|c|}
\hline \multirow{2}{*}{\multicolumn{2}{|c|}{ Variables }} & \multicolumn{2}{|c|}{ implant retained obturator } & \multirow[t]{2}{*}{ Statistics ( $\mathrm{p}$ value) } \\
\hline & & BEA & BAR AND CLIP & \\
\hline \multirow{4}{*}{ Mechanical } & Baseline & $14.42 \pm 0.62$ & $12.35 \pm 1.05$ & \multirow[t]{8}{*}{$\mathrm{P}>0.05$} \\
\hline & 90 cycle & $13.75 \pm 0.77$ & $11.28 \pm 0.88$ & \\
\hline & 270 cycle & $9.14 \pm 0.28$ & $7.77 \pm 0.63$ & \\
\hline & 540 cycle & $8.84 \pm 0.75$ & $7.46 \pm 0.43$ & \\
\hline \multirow{4}{*}{ Aging } & 810 cycle & $7.52 \pm 0.41$ & $6.46 \pm 0.52$ & \\
\hline & 1080 cycle & $6.86 \pm 0.50$ & $6.36 \pm 0.23$ & \\
\hline & 1620 cycle & $5.81 \pm 2.03$ & $4.41 \pm 0.71$ & \\
\hline & 2160 cycle & $4.82 \pm 1.15$ & $4.38 \pm 0.35$ & \\
\hline
\end{tabular}




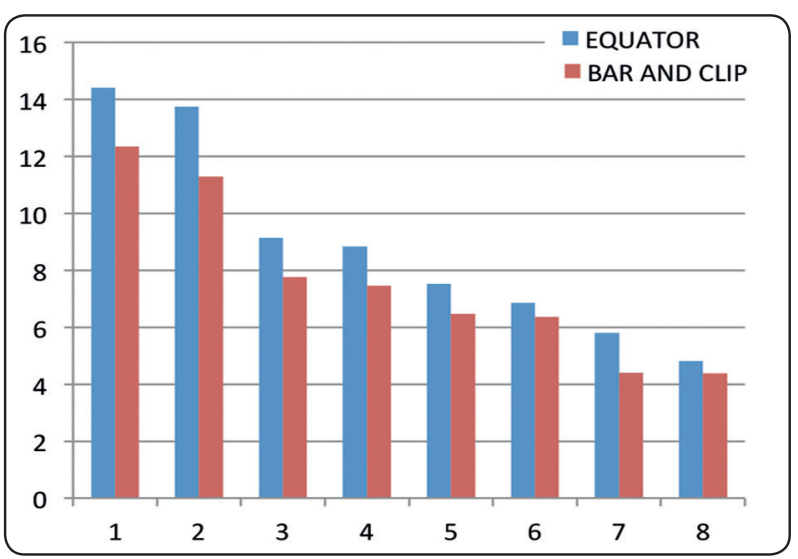

Fig. (3) Histogram of retention force mean values for implant retained obturator as function of attachment and mechanical aging

\section{II-Stress analysis results}

In this study another comparison was made between bar and clip design versus BEA in case of implant retained maxillary obturator to detect the difference in micro-strain values when a vertical load was applied at posterior intact side (level of second molar), anterior intact side (level of central incisor) and posterior defect side (level of second molar) for the two selected treatment modalities. $\mathrm{P}$ values $\leq 0.05$ are considered to be statistically significant in all tests.

TABLE (4) Comparison of $\mu$-strain results $($ Mean \pm SD) between both groups when applying load at posterior intact side.

\begin{tabular}{|c|c|c|c|c|}
\hline \multirow{2}{*}{ Variable } & \multicolumn{4}{|c|}{ Post intact } \\
\cline { 2 - 5 } & Mesial (1) & Distal (2) & Buccal (3) & Palatal (4) \\
\hline Bar\&clip & $39 \pm 4$ & $-240 \pm 7$ & $10 \pm 3$ & $-103 \pm 6$ \\
\hline BEA & $44 \pm 5$ & $-277 \pm 5$ & $11 \pm 3$ & $-136 \pm 1$ \\
\hline $\begin{array}{c}\text { Student } \\
\text { t-test }\end{array}$ & $0.034^{*}$ & $0.0009^{*}$ & $0.3929 \mathrm{~ns}$ & $0.0001^{*}$ \\
\hline
\end{tabular}

ns; non-significant. *; significant.

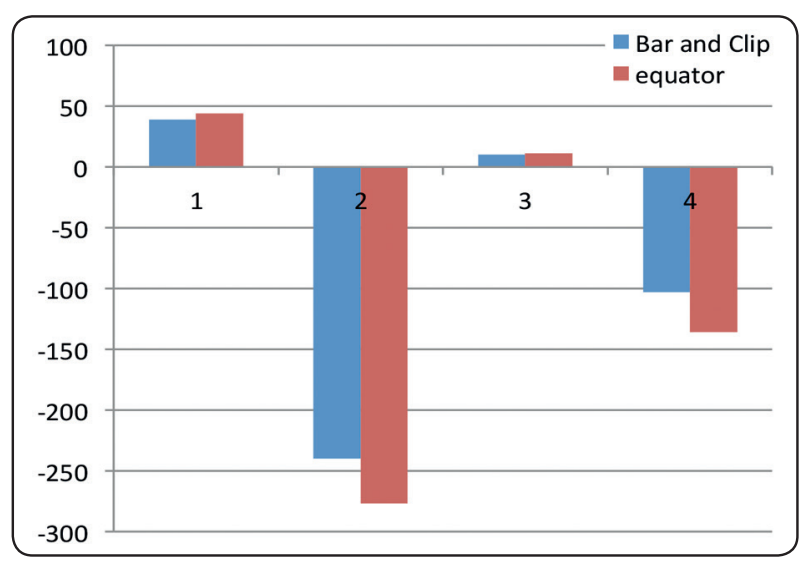

Fig. (4) Comparison of $\mu$-strain results (Mean $\pm \mathrm{SD}$ ) between both groups when applying load at posterior intact side.

TABLE (5) Comparison of $\mu$-strain results $(\mathrm{Mean} \pm \mathrm{SD})$ between both groups when applying load at anterior intact side.

\begin{tabular}{|c|c|c|c|c|}
\hline \multirow{2}{*}{ Variable } & \multicolumn{4}{|c|}{ Ant intact } \\
\cline { 2 - 5 } & Mesial(1) & Distal(2) & Buccal(3) & Palatal(4) \\
\hline $\begin{array}{c}\text { Bar and } \\
\text { clip }\end{array}$ & $-295 \pm 4$ & $86 \pm 9$ & $-28 \pm 8$ & $-132 \pm 9$ \\
\hline BEA & $-172 \pm 14$ & $79 \pm 6$ & $-16 \pm 2$ & $-142 \pm 5$ \\
\hline $\begin{array}{c}\text { Student } \\
\text { t-test }\end{array}$ & $<0.001 *$ & $<0.001 *$ & $0.001 *$ & $<0.001 *$ \\
\hline
\end{tabular}

ns; non-significant . *; significant .

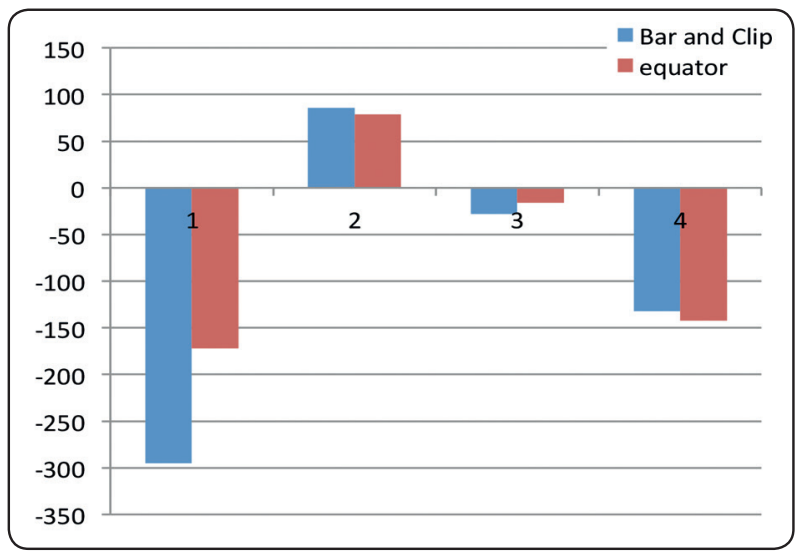

Fig. (5) Comparison of $\mu$-strain results (Mean $\pm \mathrm{SD}$ ) between both groups when applying load at anterior intact side. 
TABLE (6) Comparison of $\mu$-strain results $($ Mean \pm SD) between both groups when applying load at posterior defect side.

\begin{tabular}{|c|c|c|c|c|}
\hline \multirow{2}{*}{ Variable } & \multicolumn{4}{|c|}{ Post defect } \\
\cline { 2 - 5 } & Mesial(1) & Distal(2) & Buccal(3) & Palatal(4) \\
\hline $\begin{array}{c}\text { Bar and } \\
\text { clip }\end{array}$ & $-79 \pm 3$ & $-23 \pm 2$ & $-49 \pm 3$ & $-31 \pm 1$ \\
\hline BEA & $-84 \pm 9$ & $-20 \pm 4$ & $-69 \pm 4$ & $-25 \pm 2$ \\
\hline $\begin{array}{c}\text { Student } \\
\text { t-test }\end{array}$ & $0.008^{*}$ & $0.001^{*}$ & $0.001^{*}$ & $<0.001^{*}$ \\
\hline
\end{tabular}

ns; non-significant . *; significant.

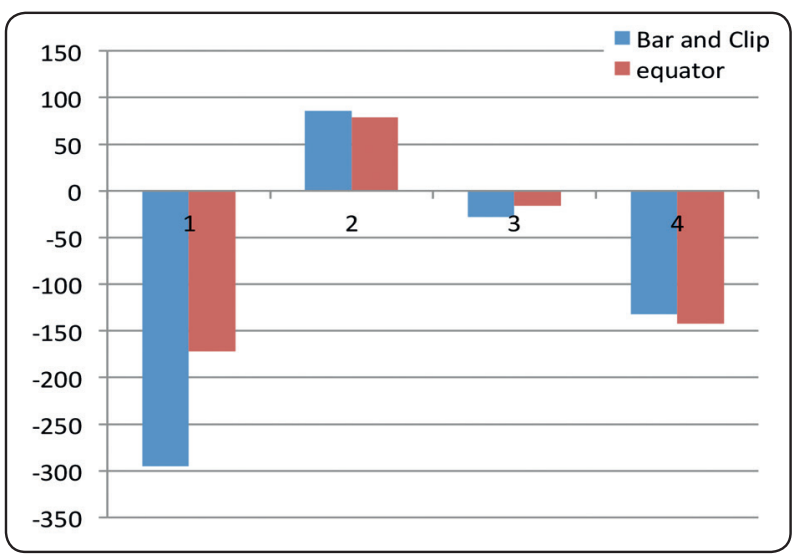

Fig. (6) Comparison of $\mu$-strain results $($ Mean \pm SD) between both groups when applying load at posterior defect side.

\section{The results showed that when applying load at :}

\section{1- The posterior intact side:}

Mesially; it was found that Bar and clip recorded statistically significant lower $\mu$-strain mean value than the BEA one.

Distally; it was found that Bar and clip recorded statistically significant higher $\mu$-strain mean value than the BEA one.

Buccally; it was found that Bar and clip recorded statistically non-significant lower $\mu$-strain mean value than the BEA one.
Palatally; it was found that Bar and clip recorded statistically significant higher $\mu$-strain mean value than the BEA one.

\section{2- Anterior intact site}

Mesially; It was found that BEA recorded statistically significant lower $\mu$-strain mean value than the Bar and clip one.

Distally; It was found that BEA recorded statistically significant lower $\mu$-strain mean value than the Bar and clip one.

Buccally; It was found that BEA recorded statistically significant lower $\mu$-strain mean value than the Bar and clip one.

Palatally; It was found that Bar and clip recorded statistically significant lower $\mu$-strain mean value than the BEA one.

\section{3-Posterior defect side}

Mesially; it was found that Bar and clip recorded statistically significant lower $\mu$-strain mean value than the BEA one.

Distally; It was found that BEA recorded statistically significant lower $\mu$-strain mean value than the Bar and clip one.

Buccally; It was found that Bar and clip recorded statistically significant lower $\mu$-strain mean value than the BEA one.

Palatally; It was found that BEA recorded statistically significant lower $\mu$-strain mean value than the Bar and clip one.

\section{DISCUSSION}

In-vitro studies have been used more widely than the in-vivo studies as it can be repeated under the same conditions of teeth, supporting tissues of bone and periodontal ligaments and residual ridge including quality and quantity of bone and covering mucosa which vary from individual to another. ${ }^{(12)}$ 
Aramany Class I maxillary defect was selected for this study because it is the most challenging cases due to lack of support, retention, and stability particularly the completely edentulous ones.(13) For many years prosthodontists tried different ways to achieve better retention for cases that have undergone extensive maxillectomy. After the development of dental implants, this problem appeared to have been solved. ${ }^{(14)}$

One of the main drawbacks of conventional maxillary obturator for edentulous patient is multi directional movements and stresses exerted during function. Placements of osseointegrated implants have a dramatic effect on the function of the prosthesis for the edentulous maxillectomy patients as implants provide retention, enhance support, and improve stability of the obturator prosthesis.Three implants were inserted in the pre-maxillary region of the intact side because the anterior maxillary segment is opposite to the most retentive portion located along the posterior lateral wall of the defect. In addition, a satisfactory bone quality and quantity can be found in the premaxillallry region. ${ }^{(15)}$

Bar attachment had been used to splint implants that support obturators for edentulous maxilla. ${ }^{(16)}$.

Bar with equator attachment which is a low profile attachment and can provide solution in cases with limited inter-arch space was selected to compare it with bar and clip attachment .

The obturator was constructed from a combination metal and acrylic to resist fracture, maintain dimensional stability throughout the study and enable the use of the same prosthesis for both attachment systems.

The obturator had also a metal ring to accommodate the tip of loading pin of universal testing machine and prevent its slippage in order to ensure reproducibility and accuracy of loading position.
The surface of the denture bearing area was replaced by a 2 -mm thickness layer of self-cured silicon soft liner to simulate the viscoelastic behavior of mucous membrane covering the residual ridge ${ }^{(17)}$

The universal testing machine was used to test the retention forces because of its accuracy, reliability and reproducibility.

The retentive forces of each retainer type was measured based on the assumption that patient removes the prosthesis three times daily. Retention was evaluated at baseline (T0), after 90 cycle (T1), 270 cycles (T2), 540 cycles (T3), 810cycles (T4), 1080 cycles (T5), 1620 cycles (T6) and 2160 cycles (T7). These measurements of insertion and removal simulating two years period of using the attachment.

The data obtained in the current study confirm previous findings concerning the effect of aging on retentive force value. The results in general showed a reduction of retention force magnitude with time (insertion and removal cycles) for both types of attachments and this can be attributed to the wear occurred in the nylon cap or bar clip. The maximum retention force result of this study showed that there was no significant difference between the two variables of implant- retained obturator.

Strain gauge experiments have been used to evaluate stresses induced by the selected type of attachments. They are most widely used in experimental mechanics to evaluate strain at a point on engineering structures. The strain sensitivity is evaluated as a function of the relative change in dimension and in the basic resistance of a material when it is stretched under load ${ }^{(18)}$.

During model preparation for strain gauge installation, $1 \mathrm{~mm}$ of acrylic resin was left all around the implants, this amount was recommended to maintain sufficient rigidity around these structures, and allow for placement of the measuring grit of the gauge closer to the load carrying structures, thereby enhancing its sensitivity to the microstrain changes that occurred as a result of load application ${ }^{(19)}$. 
Since the used strain gauges were temperature compensated for plastic, dummy gauges was not used for temperature compensation. ${ }^{(20)}$.

The moderate masticatory forces for implant retained overdenture patients were found to be about 100 Newton hence, the strain meter was set to record the micro-strain readings produced by such a load. ${ }^{(21,22,23)}$

The applied load was a static not a dynamic one, because it had been almost impossible to reproduce the chewing pattern in cases of in-vitro experiments. ${ }^{(24)}$

After each loading cycle a five minutes pause was allowed to the successive ones as recommended ${ }^{(25)}$. this allow for rebound of the deformation that occurred in the acrylic resin and the polyvinyl siloxane material simulating the mucosa following load application that could affect the results.

Comparison between Bar and clip \& BEA attachments at different loading points which were at posterior intact side, anterior intact side and posterior defect side. It was noticed that bar and clip recorded less micro-strain values than BEA in most of surfaces at different points of loading specially when applying the load on the posterior intact side.

As a fact the intact side particularly the posterior intact side is considered the preferable side for chewing in patients receiving maxillofacial prosthesis. Accordingly our readings for the intact side showed that bar and clip design gives a lesser micro strain values than that of BEA design. Also this might be attributed to the less leverage action exerted on the implants and overlying bar, as there is no extra height as that in case of the Equator attachment design. The extra height of the Equator attachment increases the leverage action on the implants and consequently increases the microstrain values.

The data obtained from the anterior intact side; showed that the BEA design recorded lesser micro strain values than that of bar and clip design. But usually the anterior loading point is not important as that of posterior one except in situation of edge to edge anterior teeth.

The data obtained from the posterior defect side; showed lesser micro strain values for the bar and clip design at the mesial and buccal surfaces than that of BEA, while higher values at the distal and palatal. And these readings at the posterior defect side need further researches to be clarified.

\section{CONCLUSION}

1- The retention force of Bar and clip was slightly lesser than BEA at any given cycle of insertion and removal.

2- Reduction of mean retentive force continues to occur over time within each group.

3- Bar and clip recorded less micro-strain values than BEA at most of the surfaces specially when applying the load on the posterior intact side.

\section{REFERENCES}

1- Chalian V, Barnett M. A new technique for constructing a one-piece hollow obturator after partial maxilllectomy. J Prosth Dentistry. 1972; 28: 448

2- Abhilasha S Bhasin, Virendra Singh, Sneha S Mantri. Rehabilitation of patient with acquired maxillary defect using a closed hollow bulb obturator. Indian J Palliat Care. 2011; 17:70-73.

3- Futran N D, Mendez E. Developments in reconstruction of midface and maxilla. Lancet Oncol. 2006; 7: 249-58.

4- Mayank Singh, Akshay Bhushan, Narendra Kumar, Sharad Chand. Obturator prosthesis for hemimaxillectomy patients. Nati J Maxillofac Surg. 2013; 4:117-20.

5- Murat S, Gurbuz A, Isayev A, Dokmez B, Cetin U. Enhanced retention of maxillofacial prosthetic obturator using precision attachment. Eur J Dent. 2012;6:2127

6- Mehmood Hussain, Nazia Yazdanie, Syed Kashif Naqvi. Achievement of retention in maxillary obturators. Pakistan Oral \& Dental J. 2013; 33:3.

7- Nishimura, Zlotolow I, Esposito S, Beumer J. Osseo integration of implants placed into non irradiated and irradiated frontal bone. In: Proceedings of the 1st International Congress on Maxillofacial Prosthetics. eds.1995. 
8- Beumer III J,Curtis TA,Marunick MT. Maxillofacial rehabilitation prosthodontics and Surgical consideration . St.Louis, MO, Ishiyaku Euro America,1996,258.

9- Carpentieri J. Treatment options for the edentulous mandible: Clinical application of the two-implant overdenture. Pract Proced Aesthet Dent. 2004; 16(2):105-12.

10- Misch C: Dental implant prosthetics. Elsevier Mosby Co., St Louis, Missouri. 2005; pp 71 - 77, 219 - 223, 253-255, 328 - 332, 482-486.

11- Roumanas E, Nishimura R, Beumer J. Use of osseointegrated implants in the maxillary resection patient. In: Proceedings of the 1st International Congress on Maxillofacial Prosthetics. Zlotolow I, Esposito S, Beumer J , eds. 1995.

12- Asundi AA, Kishen A. A strain gauge and photoelastic analysis of an in vivo strain and in-vitro stress distribution in human dental supporting structures. Arch Oral Biol. 2000; 45:543.

13- Keyf F. Obturator prosthesis for hemimaxillectomy patients. J Oral Rehab. 2001; 28:821-29.

14- Schmidt BL, Pogrel MA, Young CW. Reconstruction of extensive maxillary defects using zygomaticus implants. J Oral Maxillofac Surg. 2004; 62: 82-9.

15- Roumanas E, Nishimura R, Beumer J. Use of osseointegrated implants in the maxillary resection patient. In: Proceedings of the 1st International Congress on Maxillofacial Prosthetics. Zlotolow I, Esposito S, Beumer J , eds.1995.

16- Fukuda M, Takahashi T, Nagai H. Implant-supported edentulous maxillary obturators with milled bar attachments after maxillectomy. J Oral maxillofac Surg. 2004; 62:799-805.
17- Agamy EM. Stresses transmitted to the principle abutment in unilateral distal extension base partial denture. M.S.C,1997.

18- Jaeger R and Dietrich M. Measuring masticatory forces with strain gauges. R.A.M. 1991; 7: 39.

19- Rady A. Stress analysis induced by distal extension prosthesis with extended extracoronal attachment; thesis for the master degree, Cairo university, 2006.

20- Steggaroui R, khraisat A, Nomura S ,Miyakawa O. Influence of Super structure material on strain around an implant under two loading conditions: A technical investigation. Int J oral maxillofac Implants. 2004; 19:819.

21- Joseph A.Porter,Vicki c.petropolus,John B.Bruski. Comparison of load distribution for implant overdenture attachments. Int J Oral Maxillofac Implant. 2002; 17:651-62.

22- Goiato MC, Ribeiro Pdo P, Pellizzer EP, Pesqueira AA, Haddad MF, Dos Santos DM, Moreno A. Photoelastic analysis to compare implant-retained and conventional obturator dentures. J Biomed Opt. 2012; 17:061203.

23- Pesqueira AA, Goiato MC, Dos Santos DM, Haddad MF, Andreotti AM, Moreno A. Stress analysis in oral obturator prostheses: imaging photoelastic. J Biomed Opt. 2013; 18:106009.

24- Pezzoli M, Appendino P, Calcagno M, Celasco L, Modica R. Load transmission evaluation by removable distal extension partial dentures using holographic interferometry J dent. 1993; 21:312.

25- Tokuhisa M, Matsushita Y, Koyano K. In vitro study of a mandibular implant overdenture retained with ball, magnet or bar attachments:comparison of load transfer and denture stability. Int J Prosthodont. 2003; 16:128. 